\title{
Incidence, organ dysfunction and mortality in severe sepsis: a Spanish multicentre study
}

\author{
Jesús Blanco 1,2, Arturo Muriel-Bombín1, Víctor Sagredo ${ }^{3}$, Francisco Taboada ${ }^{4}$, Francisco Gandía ${ }^{5}$, \\ Luís Tamayo6, Javier Collado6, Ángel García-Labattut7, Demetrio Carriedo8, Manuel Valledor9, \\ Martín De Frutos ${ }^{10}$, María-Jesús López ${ }^{11}$, Ana Caballero ${ }^{12}$, José Guerra ${ }^{13}$, Braulio Álvarez ${ }^{14}$, \\ Agustín Mayo ${ }^{15}$, Jesús Villar $2,16,17$ for the Grupo de Estudios y Análisis en Cuidados Intensivos \\ (G.R.E.C.I.A.)
}

\author{
1 Critical Care Department, Nuevo Hospital Universitario Rio Hortega, Calle Dulzaina s/n, 47012 Valladolid, Spain \\ ${ }^{2}$ CIBER de Enfermedades Respiratorias (Instituto de Salud Carlos III), Carretera Soller Km. 12, 07110 Mallorca, Spain \\ ${ }^{3}$ Critical Care Department, Hospital Clínico Universitario de Salamanca, Paseo de San Vicente 182, 37007 Salamanca, Spain \\ ${ }^{4}$ Critical Care Department, Hospital Central de Asturias, Calle Celestino Villamil s/n, Oviedo, 33006 Asturias, Spain \\ ${ }^{5}$ Critical Care Department, Hospital Clínico Universitario de Valladolid, Avenida Ramón y Cajal 3, 47005 Valladolid, Spain \\ ${ }^{6}$ Critical Care Department, Hospital Río Carrión, Calle Donantes de Sangre s/n, 34005 Palencia, Spain \\ ${ }^{7}$ Critical Care Department, Hospital General de Soria, Carretera de Logroño s/n, 42004 Soria, Spain \\ ${ }^{8}$ Critical Care Department, Complejo Hospitalario de León, Calle Altos de Nava s/n, 24008 León, Spain \\ ${ }^{9}$ Critical Care Department, Hospital de San Agustín, Camino Heros 4, Avilés, 33410 Asturias, Spain \\ ${ }^{10}$ Critical Care Department, Hospital General Yagüe, Avenida del Cid Campeador 96, 09005 Burgos, Spain \\ ${ }^{11}$ Critical Care Department, Hospital General de Segovia, Carretera de Avila s/n, 40002 Segovia, Spain \\ ${ }^{12}$ Critical Care Department, Hospital Virgen de la Concha, Avenida Requejo 35, 49022 Zamora, Spain \\ ${ }^{13}$ Critical Care Department, Hospital de Cabueñes, Calle de los Prados 395, Gijón, 33394 Asturias, Spain \\ ${ }^{14}$ Critical Care Department, Hospital del Bierzo, Calle Médicos sin Fronteras 7, Ponferrada, 24411 León, Spain \\ ${ }^{15}$ Statistics Department, School of Medicine (University of Valladolid), Avenida Ramón y Cajal 7, 47005 Valladolid, Spain \\ ${ }_{16}$ Multidisciplinary Organ Dysfunction Evaluation Research Network, Research Unit, Hospital Universitario Dr. Negrin, Barranco de la Ballena s/n, \\ 35010 Las Palmas de Gran Canaria, Spain \\ ${ }_{17}$ Keenan Research Center, St. Michael's Hospital, 30 Bond Street, Toronto, Ontario M5B 1W8, Canada
}

Corresponding author: Arturo Muriel-Bombín, amuriel@hurh.sacyl.es

Received: 15 Sep 2008 Revisions requested: 1 Nov 2008 Revisions received: 26 Nov 2008 Accepted: 17 Dec 2008 Published: 17 Dec 2008

Critical Care 2008, 12:R158 (doi:10.1186/cc7157)

This article is online at: http://ccforum.com/content/12/6/R158

(c) 2008 Blanco et al.; licensee BioMed Central Ltd.

This is an open access article distributed under the terms of the Creative Commons Attribution License (http://creativecommons.org/licenses/by/2.0), which permits unrestricted use, distribution, and reproduction in any medium, provided the original work is properly cited.

\begin{abstract}
Introduction Sepsis is a leading cause of admission to noncardiological intensive care units (ICUs) and the second leading cause of death among ICU patients. We present the first extensive dataset on the epidemiology of severe sepsis treated in ICUs in Spain.

Methods We conducted a prospective, observational, multicentre cohort study, carried out over two 3-month periods in 2002. Our aims were to determine the incidence of severe sepsis among adults in ICUs in a specific area in Spain, to determine the early (48 h) ICU and hospital mortality rates, as well as factors associated with the risk of death.
\end{abstract}

Results A total of 4,317 patients were admitted and 2,619 patients were eligible for the study; $311(11.9 \%)$ of these presented at least 1 episode of severe sepsis, and 324 (12.4\%) episodes of severe sepsis were recorded. The estimated accumulated incidence for the population was 25 cases of severe sepsis attended in ICUs per 100,000 inhabitants per year. The mean logistic organ dysfunction system (LODS) upon admission was 6.3; the mean sepsis-related organ failure assessment (SOFA) score on the first day was 9.6. Two or more organ failures were present at diagnosis in $78.1 \%$ of the patients. A microbiological diagnosis of the infection was reached in 209 episodes of sepsis $(64.5 \%)$ and the most common clinical diagnosis was pneumonia (42.8\%). A total of 
169 patients (54.3\%) died in hospital, 150 (48.2\%) of these in the ICU. The mortality in the first $48 \mathrm{~h}$ was $14.8 \%$. Factors associated with early death were haematological failure and liver failure at diagnosis, acquisition of the infection prior to ICU admission, and total LODS score on admission. Factors associated with death in the hospital were age, chronic alcohol abuse, increased McCabe score, higher LODS on admission, $\triangle$ SOFA 3-1 (defined as the difference in the total SOFA scores on day 3 and on day 1 ), and the difference of the area under the curve of the SOFA score throughout the first 15 days.

Conclusions We found a high incidence of severe sepsis attended in the ICU and high ICU and hospital mortality rates. The high prevalence of multiple organ failure at diagnosis and the high mortality in the first $48 \mathrm{~h}$ suggests delays in diagnosis, in initial resuscitation, and/or in initiating appropriate antibiotic treatment.

\section{Introduction}

Sepsis is among the leading causes of admission to intensive care units (ICUs). Care for patients with sepsis represents a great economic burden [1] as extraordinary resources are devoted to developing and evaluating potential treatments as well as to studying the systemic inflammatory response and multiple organ failure that are characteristic of severe sepsis. The absence of clear definitions and diagnostic criteria for sepsis has hindered the advancement of epidemiological and clinical knowledge about this condition [2]; thus, clinical and therapeutic studies have often compiled data that are difficult to compare and extrapolate to clinical practice.

A review of studies evaluating the epidemiology of sepsis shows a very high prevalence, both among all hospitalised patients (one-third) and among those admitted to ICUs (over $50 \%$ ). More than half of all septic patients develop severe sepsis and a quarter develop septic shock; thus, $10 \%$ to $15 \%$ of all patients admitted to ICUs develop septic shock [3]. The incidence of sepsis in studies reported in the last 10 years ranges from $9 \%$ to $37 \%$ of all patients admitted to the ICU [48]. The overall incidence of sepsis is approximately 300 cases/ $10^{5}$ inhabitants/year in the USA [9]. The overall incidence of sepsis reported in Spain is 367 cases $/ 10^{5}$ inhabitants/year, including 104 cases of severe sepsis/105 inhabitants/year and 44 cases of sepsis attended in the ICU/105 inhabitants/year [10]. Martin et al. retrospectively documented 10,319,418 cases of sepsis among 750 million patients hospitalised in the USA between 1979 and 2000 [1]. A total of $27.1 \%$ of all patients admitted to ICUs in England, Wales, and Northern Ireland between 1995 and 2000 met the criteria for severe sepsis during the first $24 \mathrm{~h}$ after admission [11]. Another study found the incidence of septic shock among patients admitted to ICUs between 1993 and 2000 was 8.2\% [12]. In recent years, the reported incidence of severe sepsis in patients admitted to ICUs ranged from $11.8 \%$ to $16.6 \%$ [13,14]. Of all episodes of infection recorded in ICUs, $28 \%$ are associated with sepsis, $24 \%$ with severe sepsis, and $30 \%$ with septic shock [15].

Published mortality rates for sepsis range from $28 \%$ to $56 \%$ [4-8]. The most recently published series report mortality rates ranging from $28 \%$ to $30 \%$ in mixed ICU populations $[9,13,16]$; 30 -day mortality rates range from $32.4 \%$ to $35.5 \%[13,14]$, and in-hospital mortality may be as high as 47\% [11]. Various factors have been associated with increased risk of death: inappropriate antibiotic use, the presence of comorbidities and shock, the need for vasoactive agents, multiple organ dysfunction, neutropoenia, Candida or Enterococcus bacteraemia, and intra-abdominal, pulmonary, or unknown location infection $[9,11,17]$.

We present the first extensive dataset on the epidemiology of severe sepsis treated in the ICU in Spain. The study design and data collection were carried out prior to the publication of the Surviving Sepsis Campaign (SSC) Guidelines for management of severe sepsis and septic shock [18] and before the approval of activated protein $\mathrm{C}$ use in Spain.

\section{Materials and methods Primary objectives}

Our primary goals were: (i) to determine the incidence of severe sepsis among adults in ICUs at general hospitals in a specific geographical health care area of Spain, and (ii) to determine the early ( $48 \mathrm{~h}$ ), ICU, and hospital mortality rates as well as the factors associated with the risk of death in these patients.

\section{Secondary objectives}

Our secondary outcomes were (i) to determine the frequency of different types of organ dysfunction when severe sepsis is diagnosed; (ii) to study the evolution of organ dysfunction throughout the septic process; (iii) to determine the types of infection (acquisition and microbiology) involved, and (iv) to determine the frequency of other factors associated with severe sepsis, including both clinical (comorbidities, shock) and therapeutic factors.

\section{Design and data collection}

This was a prospective, observational, multicentre, cohort study. The study protocol was approved by the Ethics Committee of the coordinating centre (Hospital Universitario Rio Hortega, Valladolid, Spain). This approval is legally valid in Spain for all others participating centres. The study was considered an audit and informed consent was waived. After the inclusion, all patients (or their legal representatives) were asked for informed written consent for blood withdrawal of a $10 \mathrm{ml}$ sample for further analysis. The study was carried out over two 3-month periods, from 1 April to 30 June 2002, and from 1 October to 30 December 2002, in 14 ICUs in 13 Span- 
ish hospitals (10 in the region of Castilla y Leon and 3 in the region of Asturias) belonging to the public healthcare network. All patients were screened for severe sepsis on ICU admission and daily thereafter. We recorded all consecutive episodes of severe sepsis, including both cases in which the episode was the reason for admission to the ICU and episodes diagnosed in patients already admitted to the ICU for any other reason.

All data were collected on standardised forms by the physicians (members of the Grupo de Estudios y Análisis en Cuidados Intensivos (GRECIA)) responsible for the study in each ICU (see Additional file 1 for a list of members of the GRECIA group); all were specialised in intensive care medicine and had extensive experience in the diagnostic criteria for severe sepsis. Data forms were sent to a custom-built Access database (Microsoft, Redmond, WA, USA) at the coordinating centre. All data related to physiological and biological variables were checked against standardised ranges by the medical staff at the coordinating centre. Inconsistent or extreme values were thoroughly checked and corrected before analysis. Variables recorded included the McCabe score [19] for the severity of underlying conditions and known comorbidities before severe sepsis developed. Clinical and laboratory data to enable the Acute Physiology and Chronic Health Evaluation (APACHE) II Score [20] to be calculated were collected the first $24 \mathrm{~h}$ after ICU admission. The Logistic Organ Dysfunction System (LODS) [21] score was calculated at day 0 (D0), on the basis of the data recollected from inclusion to 24:00 of the same day. The Sepsis-related Organ Failure Assessment (SOFA) [22] score was calculated on days 1, 3, 7, 11, and 15 (D1, D3, D5, D11, D15) from inclusion to evaluate the progression of multiple organ dysfunction. In all cases, unavailable clinical or laboratory data were assigned a value of $\mathrm{O}$ in the analysis. Neurological status was determined using the Glasgow Coma Scale (GCS) prior to sedation.

Patients were considered to have an infection if this was microbiologically documented according to the standard definitions of the Centers for Disease Control and Prevention (CDC) [23] or at least clinically suspected requiring evidence such as the presence of white blood cells in a normally sterile body fluid, perforated viscus, chest X-ray consistent with pneumonia and associated with purulent tracheal secretion, or a clinical syndrome associated with a high probability of infection. Infection was classified according to the mode of acquisition (community, hospital, or ICU), to the method of diagnosis (suspected, clinically documented through imaging or surgical findings, or microbiologically documented), to the microorganisms responsible when these were isolated, and to the organ(s) affected. We recorded whether the initial antibiotic therapy was appropriate according to the antibiogram for the microorganisms responsible when these were isolated. We recorded the dates of admission to the hospital and to the $\mathrm{ICU}$, the date and time of inclusion in the study estimated from the time the attending physician considered that the patient fulfilled the criteria for severe sepsis, and the date of death if the patient died or the date of discharge from the ICU and from the hospital if the patient survived.

\section{Calculation of the accumulated incidence}

Each hospital belonging to the Public Health Care Network in Spain provides medical care for a specific geographical healthcare area with a known population. To avoid bias, we calculated the overall incidence for the population from only those healthcare areas in which all existing ICUs participated in the study. Thus, data from $11 \mathrm{ICUs}$ in 10 hospitals corresponding to 10 healthcare areas were used. The total number of residents $\geq 18$ years of age in these healthcare areas was obtained from the 2001 census published by the Spanish National Statistics Institute (INE) [24]. Patients were included into the study if they were admitted to an ICU for severe sepsis during the study period or if they presented with an episode of severe sepsis during the study period after admission to the ICU for any reason. Patients $\leq 18$ years of age were excluded. Patients admitted for ischaemic heart disease, cardiac arrhythmia and heart block were excluded since they were not considered at risk for sepsis. However patients undergoing open heart surgery were considered in our patient population. Definitions for ICU type, patient categories, comorbidities, systemic inflammatory response syndrome, sepsis, severe sepsis, septic shock and organ dysfunction are outlined in Additional file 2.

\section{Statistical analysis}

Quantitative data are described as mean \pm standard deviation (SD), medians and percentiles. Comparisons were performed using the Student $t$ test or the Mann-Whitney $U$ test, as appropriate; values of $p<0.05$ were considered significant. Categorical data were analyzed by means of frequencies, percentages, and their confidence intervals. The estimated accumulated incidence of severe sepsis for the healthcare area was expressed as cases per 100,000 inhabitants per year. Patients were analyzed according to: (a) onset of severe sepsis (at admission or during hospitalisation); (b) acquisition site of severe sepsis (community, hospital, ICU); (c) type of ICU admission (medical, surgical, traumatological); (d) microbiological type and site of infection; (e) McCabe score; (f) LODS score on day 0 (D0); (g) SOFA score on day 1 (D1), day 3 (D3), day 7 (D7), day 11 (D11), and day 15 (D15). The progression of multiple organ dysfunction was assessed by sequentially calculating the SOFA score in survivors and nonsurvivors on days $1,3,7,11$, and 15 from the time of diagnosis. The standardised area under the curve (AUC) of the SOFA score over time was calculated for survivors and non-survivors and then compared using the Student ttest. Risk factors associated with ICU and hospital mortality were analyzed univariately and then multivariately by logistic regression; the degree of association with mortality was expressed as independent factors by means of odds ratios with their corresponding $95 \%$ confidence intervals. The statistical analysis was carried out by 
the staff of the coordinating centre and by a professor at the Department of Biostatistics of the Medical School at the University of Valladolid, who did not participate in collecting the data. All analyses were performed using SAS (version 8.02, SAS Institute, Cary, NC, USA) and SPSS (version 11.0.1, SPSS, Chicago, IL, USA) statistical software.

\section{Results}

A total of 4 University hospitals, 3 University-associated hospitals and 6 Community hospitals participated in the study, with a total of $164 \mathrm{ICU}$ beds and 14 ICUs (1 Medical, 12 Medical/ Surgical and 1 Cardiac Surgical). Of these 14 ICUs, 9 had coronary units.

\section{Incidence of severe sepsis}

During the study period, a total of 4,317 patients were admitted to the participating ICUs; $1,698(39.3 \%)$ of these were excluded, including 1,658 (38.4\%) because they had noninfectious heart problems and $40(0.9 \%)$ were under 18 years of age. Thus, 2,619 patients (60.7\%) were eligible for the study; $311(11.9 \% ; 95 \% \mathrm{Cl} 10.6$ to 13.1$)$ of these presented at least 1 episode of severe sepsis. A total of 324 (12.4\%; $95 \% \mathrm{Cl} 11.1$ to 13.6 ) episodes of severe sepsis were recorded: $80.8 \%$ of the episodes were diagnosed at or before ICU admission and the remaining $19.2 \%$ occurred in patients already in the ICU for various reasons. Seven patients presented two consecutive episodes of severe sepsis and three patients presented three consecutive episodes during their stay in the ICU (Figure 1).

A total of 246 episodes of severe sepsis were attended in the ICUs of the 10 hospitals that were considered for the estimation of the incidence in the general population. In 2001, a total of $1,946,130$ inhabitants over 18 years of age resided in the geographical area assigned to these hospitals; 895,593 $(46 \%)$ of these lived in urban areas, while the rest lived in rural areas [24]. The estimated accumulated incidence for the population was 25 cases of severe sepsis attended in ICUs per 100,000 inhabitants residing in the healthcare area per year.

The characteristics of the patients presenting at least one episode of severe sepsis that were included in the study are shown in Table 1. The mean (SD) APACHE II score was 25.5 $( \pm 7.1)($ median $=25)$. The mean (SD) LODS score was 6.3 $( \pm 3.6)$ (median =6); the mean (SD) SOFA score on the first day was $9.6( \pm 3.7)$ (median $=10)$. Upon admission, roughly a quarter of the patients had one, two or three organ failures respectively and $78.1 \%$ had more than two organ failures.

\section{Characteristics of the infection}

The infections were acquired in the community in $51.5 \%$, in the ICU in $19.2 \%$, and in other areas of the hospital in $29.3 \%$. Lungs were the predominant site of infection $(44.8 \%)$, followed by the abdomen $(31.5 \%)$, urinary tract $(6.2 \%)$, central venous catheter $(4.6 \%)$, soft tissues $(3.1 \%)$ and surgical
Figure 1

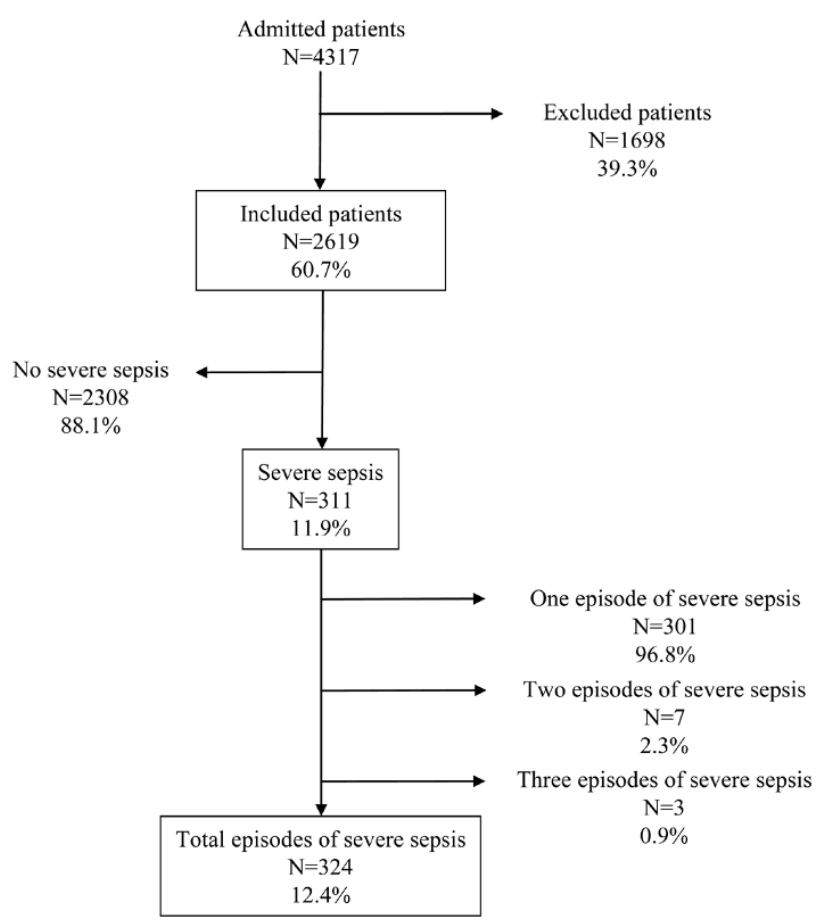

Episodes of severe sepsis recorded in the patients admitted to the ICUs.

wounds (3.1\%). The most common clinical diagnosis related to an episode of severe sepsis was pneumonia (139 episodes, $42.9 \%, 95 \% \mathrm{Cl} 37.4$ to 48.5$)$. Of these, 63 episodes were community-acquired pneumonia (19.4\%) and 76 episodes were nosocomial pneumonia (23.5\%). The second diagnosis was peritonitis not secondary to surgical intervention (47 episodes, $14.5 \%, 95 \% \mathrm{Cl} 10.9$ to 18.8 ) followed by non-surgical infection of the digestive tract in 26 episodes $(8 \%, 95 \% \mathrm{Cl} 5.3$ to 11.5$)$, bacteraemia associated with abdominal infection in 16 episodes $(4.9 \%, 95 \% \mathrm{Cl} 2.8$ to 7.9$)$ and urinary tract infection in 14 episodes $(4.3 \%, 95 \% \mathrm{Cl} 2.4$ to 7.1$)$; other diagnoses were less frequent.

A microbiological diagnosis of the infection was reached in 209 episodes of sepsis (64.5\%). Table 2 shows the frequency of the different sites of infection and of the different microorganisms isolated. The diagnosis was reached clinically in a total of 82 episodes (25.3\%), based on the clinical presentation and imaging findings in $14.5 \%$ and on surgical findings in $10.8 \%$. In the remaining 33 episodes (10.2\%), the diagnosis was highly suspicious.

Once the antibiogram was obtained, the initial treatment was considered appropriate in $165(78.9 \%)$ episodes of severe sepsis with microbiological diagnosis, and inappropriate in 39 (18.7\%) episodes. The attending physician did not indicate 
Table 1

Demographic and clinical characteristics of the 311 patients at the time of diagnosis of the first episode of severe sepsis. See definitions in the text and list of abbreviations for meaning

\begin{tabular}{|c|c|c|c|}
\hline & & Parameter & $95 \% \mathrm{Cl}$ \\
\hline & Median & IQR & \\
\hline \multirow[t]{2}{*}{ Age (years) } & 68 & 54.9 to 74.5 & \\
\hline & No. & $\%$ & \\
\hline Sex (male) & 208 & 66.9 & 61.3 to 72.1 \\
\hline \multicolumn{4}{|l|}{ McCabe score: } \\
\hline 0 & 81 & 26 & 21.2 to 31.2 \\
\hline 1 & 131 & 42.1 & 36.5 to 47.8 \\
\hline 2 & 63 & 20.3 & 15.9 to 25.1 \\
\hline 3 & 36 & 11.6 & 8.2 to 15.7 \\
\hline \multicolumn{4}{|l|}{ Category: } \\
\hline Medical & 179 & 57.6 & 51.9 to 63.1 \\
\hline Urgent surgery & 93 & 29.9 & 24.9 to 35.3 \\
\hline Scheduled surgery & 23 & 7.4 & 4.7 to 10.9 \\
\hline Traumatological & 16 & 5.1 & 3.0 to 8.2 \\
\hline \multicolumn{4}{|l|}{ Origin: } \\
\hline Medical and Surgical ward & 167 & 53.7 & 48.0 to 59.0 \\
\hline Emergency department & 67 & 21.5 & 12.5 to 21.0 \\
\hline Operating room & 51 & 16.4 & 17.1 to 26.5 \\
\hline Other & 26 & 8.3 & 5.5 to 12.0 \\
\hline \multicolumn{4}{|l|}{ Comorbidities: } \\
\hline Chronic respiratory failure & 46 & 14.8 & 11.0 to 19.2 \\
\hline Immunodeficiency & 41 & 13.2 & 9.6 to 17.5 \\
\hline Risk of bleeding & 31 & 10 & 6.9 to 13.8 \\
\hline Chronic alcoholism & 25 & 8 & 5.3 to 11.6 \\
\hline Chronic renal failure & 23 & 7.4 & 4.7 to 10.9 \\
\hline IDDM & 22 & 7.1 & 4.5 to 10.5 \\
\hline Metastatic cancer & 17 & 5.5 & 3.2 to 8.6 \\
\hline Chronic heart failure & 15 & 4.8 & 2.7 to 7.8 \\
\hline Chronic liver failure & 14 & 4.5 & 2.5 to 7.4 \\
\hline AIDS & 4 & 1.3 & 0.4 to 3.3 \\
\hline \multicolumn{4}{|l|}{ No. of comorbidities: } \\
\hline None & 140 & 45 & 39.4 to 50.7 \\
\hline One & 114 & 36.7 & 31.3 to 42.3 \\
\hline Two & 46 & 14.8 & 11.0 to 19.2 \\
\hline Three or more & 11 & 3.5 & 1.8 to 6.2 \\
\hline \multicolumn{4}{|l|}{ Organ failure: } \\
\hline Respiratory & 233 & 74.9 & 69.7 to 79.6 \\
\hline
\end{tabular}




\begin{tabular}{|c|c|c|c|}
\hline Shock & 180 & 57.9 & 52.1 to 63.4 \\
\hline Cardiovascular & 158 & 50.8 & 45.1 to 56.5 \\
\hline Renal & 124 & 39.9 & 34.4 to 45.6 \\
\hline Haematological & 69 & 22.2 & 17.7 to 27.2 \\
\hline Liver & 40 & 12.9 & 9.3 to 17.1 \\
\hline Neurological & 37 & 11.9 & 8.5 to 16.0 \\
\hline \multicolumn{4}{|l|}{ No. of organ failures: } \\
\hline One & 68 & 21.9 & 17.4 to 26.9 \\
\hline Two & 86 & 27.7 & 22.8 to 32.0 \\
\hline Three & 81 & 26 & 21.3 to 31.3 \\
\hline Four & 39 & 12.5 & 9.1 to 16.7 \\
\hline \multirow[t]{2}{*}{ Five or more } & 37 & 11.9 & 6.6 to 16.0 \\
\hline & Median & Mean (SD) & \\
\hline APACHE II score (D1) & 25 & $25.5( \pm 7.1)$ & 24.5 to 26.2 \\
\hline LODS score (D0) & 6 & $6.3( \pm 3.6)$ & 5.9 to 6.7 \\
\hline SOFA score (D1) & 10 & $9.6( \pm 3.7)$ & 9.2 to 10.0 \\
\hline
\end{tabular}

APACHE II, Acute Physiology and Chronic Health Evaluation II; Cl, confidence interval; D0: day 0; D1: day 1; IDDM, insulin-dependent diabetes mellitus; IQR: interquartile range; LODS, Logistic Organ Dysfunction System; SD, standard deviation; SOFA, Sepsis-related Organ Failure Assessment.

whether the initial treatment was appropriate in the remaining five $(2.4 \%)$ episodes.

\section{Outcome of patients}

The median hospital stay was 24 days (interquartile range: 11 to 44 days) and the median ICU stay was 10 days (interquartile range: 4 to 20 days). The hospital and ICU stays were significantly higher in survivors than in non-survivors (Table 3). Of the 311 patients included in the study, 169 patients $(54.3 \%$; $95 \% \mathrm{Cl} 48.6$ to 60.0$)$ died in the hospital and $150(48.2 \%$; $95 \% \mathrm{Cl} 42.5$ to 53.9 ) of these died in the ICU (Table 3). Figure 2 shows the cumulative hospital mortality in the total of 311 patients. Early mortality was high, $14.8 \%(95 \% \mathrm{Cl} 10.7$ to 18.9) in the first 2 days, and the mortality at 28 days was $47.9 \%$ (95\% Cl 42.2 to 53.6). At 90 days from diagnosis of severe sepsis, 167 patients (53.7\%; 95\% Cl 48.0 to 59.4 ) had died, and 13 patients were still in hospital (4.1\%), 3 in the ICU (0.9\%) and $10(3.2 \%)$ in the regular ward. Figure 3 shows the accumulated percentage of 169 non-survivors who died on the different days after inclusion in the study; $7.7 \%(95 \%$ $\mathrm{Cl} 3.4$ to 12.0 ) of the non-survivors died on day 0 , and the accumulated mortality in the non-survivors on days 2,8 , and 15 was $27.2 \%$ (95\% Cl 20.2 to 34.2 ), 53.3\% (95\% Cl 45.4 to 61.1 ) and $70.4 \%$ (95\% $\mathrm{Cl} 63.2$ to 77.6$)$, respectively.
No differences in hospital mortality rate were observed by acquisition site and admission category (Table 3 ). Figure 4 shows mortality by the number of organ failures at the time of severe sepsis diagnosis (D0).

\section{Evolution of organ dysfunction}

The mean SOFA score decreased with time ( 9.6 points on day 1 to 6.6 points on day 15), probably because some of the patients that eventually died, who had higher scores, were still alive on day 1 (Figure 5). The mean SOFA score was initially higher in patients that died than in survivors and it remained higher throughout the first 15 days. As the time intervals between SOFA scores were not equal, to compare the evolution of SOFA scores between survivors and non-survivors over time, we calculated the standardised area under the curve for both trends and compared them. The standardised value of the area under the curve for the evolution of SOFA scores over time was 5.78 (standard error of the mean $(S E M)=0.49$ ) in survivors and 9.92 (SEM $=0.30)$ in those that died. The difference between the area under the curve for those that died and those that survived was $3.14(95 \% \mathrm{Cl} 2.99$ to 5.28$)$ ( $p<$ 0.001) (Figure 5).

Risk factors for death associated with severe sepsis

The risk factors associated with death were identified in the following analyses: (a) risk factors present at diagnosis (DO) 
Table 2

Frequencies of identified microorganisms and sites of isolation

\begin{tabular}{|c|c|}
\hline & $\%$ \\
\hline Gram negative bacilli (GNB) $(n=129)$ & 50 \\
\hline E. coli & 37.2 \\
\hline Pseudomonas aeuruginosa & 20.9 \\
\hline Acinetobacter baumanii & 10.9 \\
\hline Legionella pneumophila & 7.8 \\
\hline Klebsiella pneumoniae & 3.1 \\
\hline Proteus mirabilis & 3.1 \\
\hline Serratia marcescens & 2.3 \\
\hline Haemophilus influenzae & 2.3 \\
\hline Gram positive cocci (GPC) $(n=104)$ & 40.3 \\
\hline Staphylococcus aureus & 32.7 \\
\hline Streptococcus pneumoniae & 21.2 \\
\hline Enterococcus faecalis & 9.6 \\
\hline Staphylococcus epidermidis & 7.7 \\
\hline Coagulase negative Staphylococcus & 6.7 \\
\hline Others & 22.1 \\
\hline Fungi $(n=15)$ & 5.8 \\
\hline Candida albicans & 66.7 \\
\hline Candida spp & 20 \\
\hline Pneumocystis carinii & 13.3 \\
\hline Other $(n=10)$ & 3.9 \\
\hline Clostridium perfringens & 50 \\
\hline Corinebacterium & 20 \\
\hline Clostridium ramosum & 10 \\
\hline Neisseria meningitidis & 10 \\
\hline Herpes Zoster virus & 10 \\
\hline
\end{tabular}

GNB sites:

$\begin{array}{ll}\text { Tracheal aspirations } & 33.8\end{array}$

Blood cultures 23.3

Abdomen 13.7

Serology 7

Surgical wound $\quad 5.4$

Urine 5.4

Skin 3.1

Others 3.3

GPC sites:

$\begin{array}{ll}\text { Tracheal aspirations } & 33.7\end{array}$

$\begin{array}{ll}\text { Blood cultures } & 31.7\end{array}$
Table 2 (Continued)

\begin{tabular}{lc} 
Frequencies of identified microorganisms and sites of isolation \\
\hline Abdomen & 10.6 \\
Surgical wound & 7.7 \\
Serology for pneumococci & 6.8 \\
Skin & 2.9 \\
Catheter & 2.9 \\
Others & 4.7 \\
Fungi sites: & \\
Tracheal aspiration & 26.7 \\
Urine & 26.7 \\
Bronchoalveolar lavage & 13.3 \\
Abdomen & 13.3 \\
Others & 20 \\
\hline
\end{tabular}

associated with early death (death within $48 \mathrm{~h}$ of diagnosis), (b) risk factors present at diagnosis associated with hospital mortality, and (c) risk factors associated with hospital mortality that appeared during the patient's evolution but that are not necessarily present at diagnosis.

Risk factors present at diagnosis (DO) associated with early death in the ICU $(\leq 48 h)$

In the univariate analysis, the variables that were associated with early mortality were haematological $(p=0.004)$ and liver failure $(p=0.005)$ according to the Recombinant Human Activated Protein C Worldwide Evaluation in Severe Sepsis (PROWESS) definition [16]; inappropriate initial antibiotic treatment $(p=0.03)$; acquisition site of the infection $(p=$ 0.007 ), with early mortality higher in patients with communityacquired infections than in those that acquired the infection after admission to the ICU $(25.6 \%$ vs $0 \%, p<0.001)$, and LODS score $(p=0.02)$. In the multivariate analysis, the factors independently associated with early death were haematological failure, OR $1.5,(95 \% \mathrm{Cl} 1.3$ to 3.4$)$; liver failure, OR 2, (95\% Cl 1.6 to 6.3 ); acquisition of the infection before ICU admission, OR 2.2, (95\% Cl 1.0 to 4.4); and LODS score, OR 1.2 , (95\% Cl 1.1 to 1.4$)$.

Risk factors present at diagnosis (DO) associated with hospital mortality

In the univariate analysis, sex $(p=0.05)$, age $(p=0.003)$, chronic alcohol abuse $(p=0.04)$, congestive heart failure $(p=$ $0.03)$, shock $(p=0.002)$, haematological $(p=0.01)$, neurological $(p=0.07)$ and liver failure $(p=0.04)$ according to the PROWESS definition [16], McCabe index ( $p<0.0001$ ), LODS SCORE $(p<0.0001)$, and the number of comorbidities $(p<0.001)$ were significantly associated with the risk of dying. Infection located in the urinary tract was associated with lower 
Critical Care Vol 12 No 6 Blanco et al.

Table 3

Outcome of 311 patients with severe sepsis

\begin{tabular}{|c|c|c|c|c|}
\hline \multirow[t]{2}{*}{ Stay from diagnosis of severe sepsis, days, median (IQR) } & & & & \multirow[t]{2}{*}{ p Value } \\
\hline & & Survivors & Non-survivors & \\
\hline Hospital & & 35 (22 to 59$)$ & 15 (7 to 30$)$ & 0.000 \\
\hline Intensive care unit (ICU) & & 12 (5 to 23$)$ & 8 (3 to 18$)$ & 0.006 \\
\hline Pre ICU & & 1.5 (0 to 7$)$ & $2(0$ to 8$)$ & 0.287 \\
\hline Post ICU & & 15 (9 to 24$)$ & 10 (4 to 28$)$ & 0.298 \\
\hline Mortality & & n (\%) & $95 \% \mathrm{Cl}$ & \\
\hline Day 28 & & $149(47.9)$ & 42.2 to 53.6 & \\
\hline ICU & & $150(48.2)$ & 42.5 to 53.9 & \\
\hline \multirow[t]{2}{*}{ Hospital } & & $169(54.3)$ & 48.6 to 60.0 & \\
\hline & $\mathrm{n}$ & Hospital death (\%) & $95 \% \mathrm{Cl}$ & \\
\hline Acquisition site: & & & & 0.655 \\
\hline Intra ICU & 51 & $30(58.8)$ & 44.2 to 72.4 & \\
\hline Hospital & 93 & $52(55.9)$ & 45.2 to 66.2 & \\
\hline Community & 167 & $87(52.1)$ & 44.2 to 59.9 & \\
\hline Admission category: & & & & 0.715 \\
\hline Scheduled surgery & 23 & $13(56.5)$ & 34.4 to 76.8 & \\
\hline Medical & 179 & $101(56.4)$ & 48.9 to 64.0 & \\
\hline Unscheduled surgery & 93 & $48(51.6)$ & 41.0 to 62.1 & \\
\hline Traumatological & 16 & $7(43.8)$ & 19.7 to 70.1 & \\
\hline Infection site: & & & & 0.008 \\
\hline Abdomen & 101 & $63(62.4)$ & 52.4 to 72.3 & \\
\hline Lung & 138 & $82(59.4)$ & 50.9 to 68.0 & \\
\hline Soft tissues & 8 & $4(50)$ & 15.7 to 84.3 & \\
\hline Surgical wound & 10 & $3(30)$ & 6.7 to 65.2 & \\
\hline Catheter related & 14 & $4(28.6)$ & 8.4 to 58.1 & \\
\hline Urinary tract & 20 & $4(20)$ & 5.7 to 43.7 & \\
\hline Others & 20 & $9(45)$ & 23.1 to 68.5 & \\
\hline
\end{tabular}

ap Value for comparison between survivors and non-survivors.

$\mathrm{Cl}$, confidence interval; IQR, interquartile range.

mortality in this subgroup of patients $(p<0.001)$. The multivariate analysis confirmed that both the severity of the acute organ dysfunction measured by total LODS score on day 0 and the severity of underlying conditions measured by the McCabe score were independently associated with the risk of dying, as were age and chronic alcohol abuse. Infection located in the urinary tract was independently associated with lower mortality compared to other infection sites (Table 4, Model 1).
To better analyze the impact on mortality of each organ or system dysfunction assessed by LODS, we introduced the score for each organ into the model independently; we observed that increased scores for the haematological, neurological, pulmonary, and renal components were significantly associated with mortality. Age and an increased McCabe score in comparison to the absence of prior chronic disease remained as independent risk factors for death (Table 4, Model 2). 


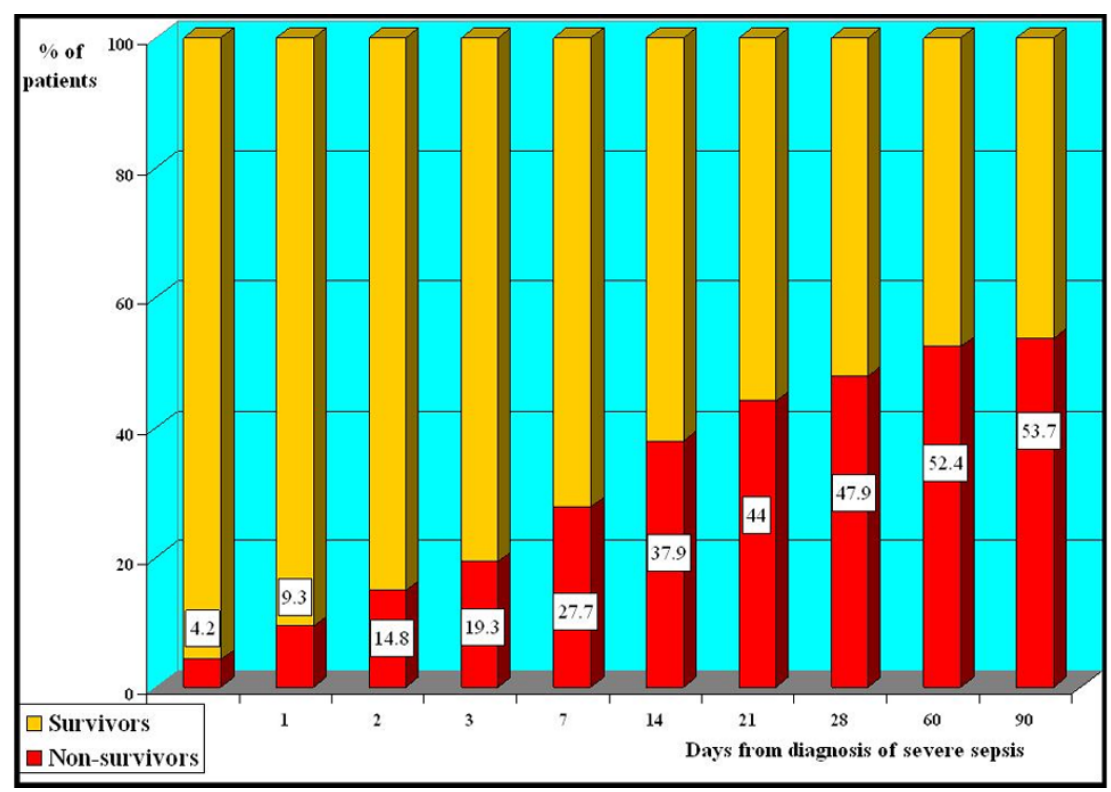

Cumulative hospital mortality. Numbers in squares: cumulative mortality in different days.

Risk factors associated with hospital mortality obtained at the time of diagnosis (DO) and overtime

When overall hospital mortality was taken as the dependent variable, the variables obtained at DO and overtime that were most strongly associated with mortality were cardiovascular dysfunction in the SOFA score on day 1 and the variable $\triangle$ SOFA 3-1, defined as the difference in the total SOFA scores on day 3 and on day 1 . An increase of 1 point on the SOFA score between day 1 and day 3 increased the risk of death by a factor of 1.324. Chronic alcohol abuse, hospital stay prior to ICU admission, and APACHE II seem to be asso-

\section{Figure 3}

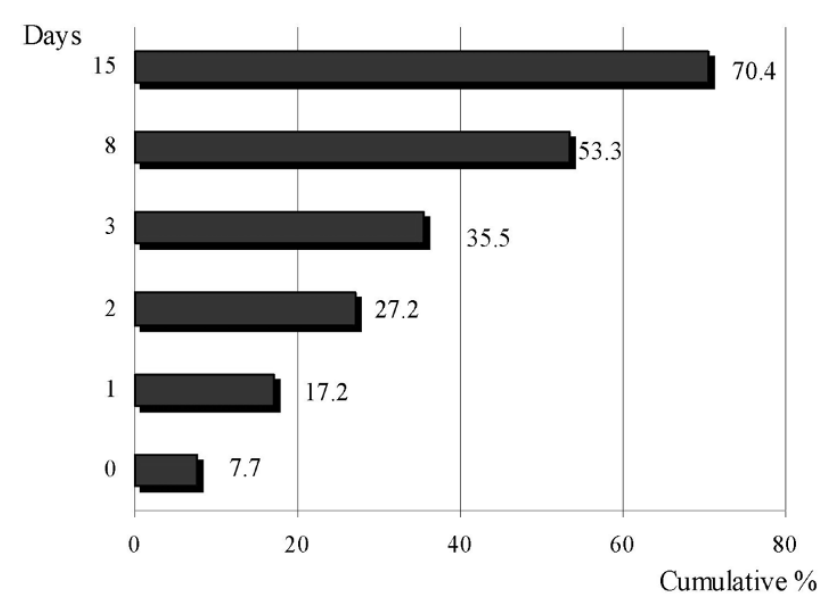

Time course of mortality in non-survivors. Cumulative percentage of non-survivors $(n=169)$ after diagnosis of severe sepsis. ciated with the risk of death; however, the 95\% confidence intervals for these variables include 1 , so their association with mortality is uncertain (Table 5).

\section{Discussion}

The most important findings of this study were: (a) the high incidence (12.4\%) of severe sepsis in the ICU and high mortality in both the ICU (48.2\%) and the hospital (54.3\%); (b) the

\section{Figure 4}

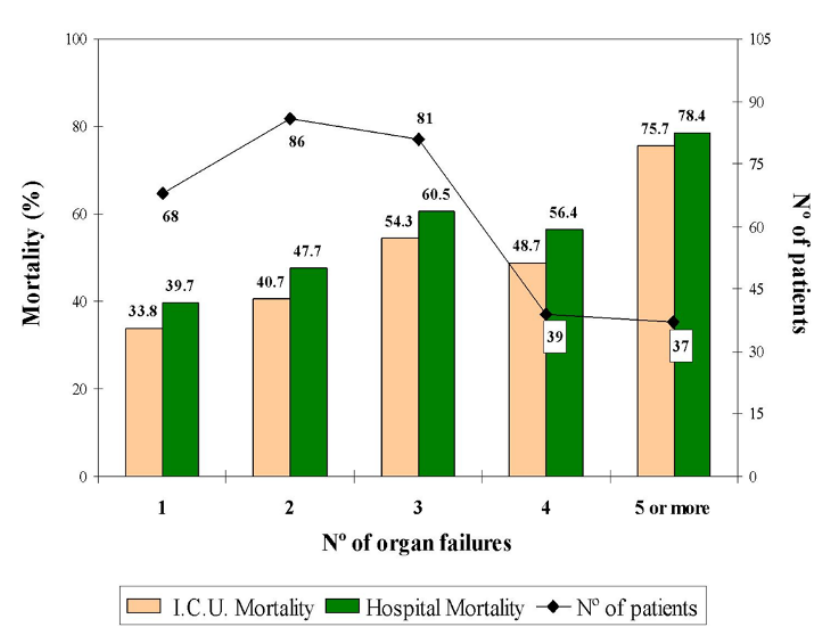

Mortality by the number of organ failures at the time of diagnosis of severe sepsis (day 0 (D0)). Organ failures defined according to Recombinant Human Activated Protein C Worldwide Evaluation in Severe Sepsis (PROWESS) study criteria [16]. ICU, intensive care unit. 
Figure 5

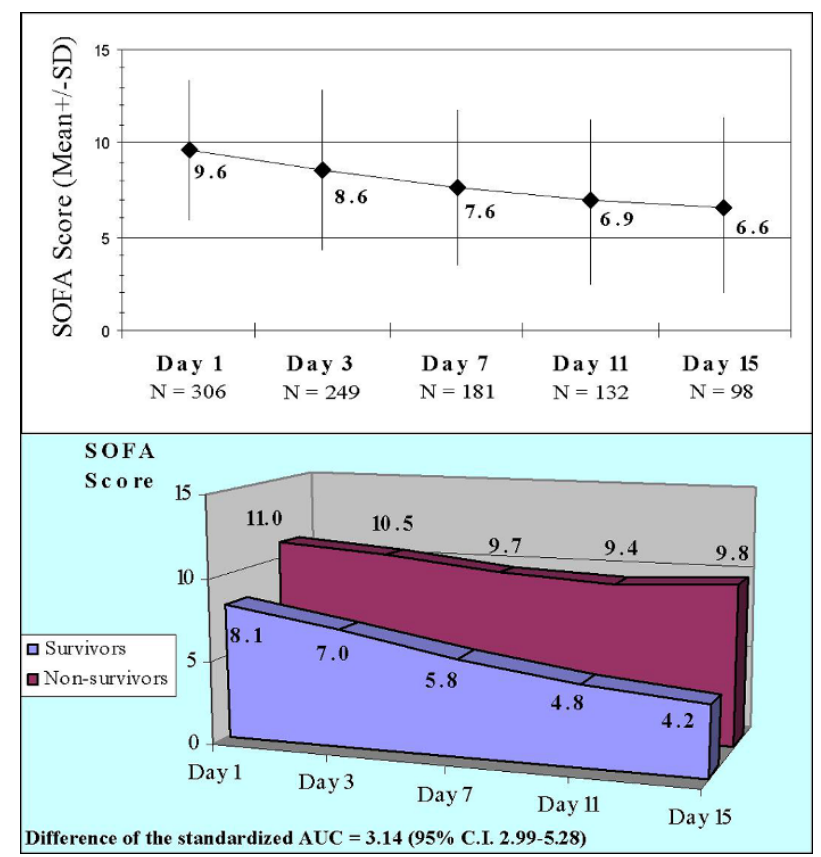

Evolution of the SOFA score over time. Upper panel: entire group of patients. Lower panel: area under the curve (AUC) of the Sepsisrelated Organ Failure Assessment (SOFA) score trends in survivors and non-survivors. $\mathrm{Cl}$, confidence interval of the difference of the standardised AUC between survivors and non-survivors; SD, standard deviation.

association of severe sepsis with long ICU and hospital stays (median 10 days and 24 days, respectively); (c) the factors associated with early death were haematological failure and liver failure at diagnosis, acquisition of the infection prior to ICU admission and total LODS score; and (d) the factors associated with death in the hospital were age, chronic alcohol abuse, increased McCabe score, increased LODS score, $\triangle$ SOFA 3-1 and the evolution of the SOFA score.

Standardised diagnostic criteria for sepsis, severe sepsis, septic shock, and organ dysfunction and failure associated with infection [2] have enabled the epidemiological evaluation of septic syndromes, as well as of their progression in recent years and of the efficacy of new treatment measures. Using these diagnostic criteria, we found an incidence of severe sepsis of $12.4 \%$, which is comparable to that of other series published in recent years and in line with the progression predicted by Martin et al. [1]. The EPISEPSIS Group [13] found an incidence of severe sepsis or septic shock of $14.6 \%$ among patients admitted to the ICU, and Finfer et al. found 11.8 cases of severe sepsis for every 100 admissions to the ICU [14]. Different authors have suggested that this progression might be related to the use of immunosuppressors, hospital malnutrition, alcoholism, cancer, diabetes mellitus, the growing invasiveness of both diagnostic and therapeutic measures, increased resistance of microorganisms, and the progressive aging of the population $[1,9,17]$. The advanced age of our population (median 68 years), the high incidence of previous immunodeficiency (13.2\%), and the presence of other risk factors such as previous alcoholism, diabetes, chronic heart failure, kidney failure, liver failure, or respiratory failure confirm this increase in risk factors.

The overall incidence of severe sepsis for the population covered by the ICUs in this study was 25 cases per 100,000 inhabitants over 18 years of age per year, a figure that is lower than the incidence reported in recently published studies. This difference might be explained by seasonal bias, differences in the populations studied, differences in access to hospitals, and/or a low rate of detection of severe sepsis. The EPISEPSIS Group [14] estimated the incidence for all France at 95 cases of severe sepsis attended in the ICU per 100,000 inhabitants per year. The recruitment period in the EPISEPSIS study was only 15 days, so this high incidence might reflect a seasonal bias; however, the wide selection of hospitals and geographical areas participating in this study lend significant weight to these results. Esteban et al. recorded cases of sepsis admitted to 3 hospitals and estimated the overall incidence for the population at 44 cases of sepsis and 33 cases of severe sepsis attended in the ICU per 100,000 inhabitants per year [10]. The study period covered 4 randomly chosen unspecified months, which might have introduced a seasonal bias. Furthermore, the population of the geographical area assigned to the hospitals that participated in the study was mainly urban, with a high percentage of transient persons and immigrants not counted in the census. In our study, the incidence reported refers to episodes of severe sepsis among patients admitted to the ICU; the study period is wider and divided into two periods to reduce the possibility of seasonal bias on the incidence. Moreover, the population is predominantly rural $(54 \%)$, with a low rate of transient persons and immigrants not counted in the census, but also with more difficulties accessing the hospitals and probably a lower rate of detection of severe sepsis before admission to the ICU.

The hospital mortality in our series (54.3\%) differs from that published in the most recent series, which ranges from $28 \%$ to $48.4 \%[9,11,13,14,16]$. However, methodological differences with our study account for much of these differences. The study by Angus et al. [9] is retrospective, from hospital records and also includes children. Padkin et al. [11] reported $47.3 \%$ mortality, but their study only includes episodes of severe sepsis that occurred during the first $24 \mathrm{~h}$ after ICU admission. The EPISEPSIS Study [14] reported a 60-day mortality of $41.9 \%$, but the outcome of $11.4 \%$ of the patients who were still hospitalised 2 months after the diagnosis of severe sepsis is unknown. The control group in the PROWESS study [16] had a mortality of 31.3\%; however, this study was a randomised controlled trial, so not all patients diagnosed with severe sepsis were included in the mortality analysis. Moreo- 
Risk factors for hospital death, present at severe sepsis diagnosis. Model 1 shows the risk factors that were independently associated with hospital death. Model 2 shows the results of a second multivariate analysis introducing the each of the variables that make up the LODS score separately

\begin{tabular}{lll}
\hline & Odds ratio & $95 \%$ Cl \\
\hline Model $1:$ & 3.14 & 1.51 to 6.54 \\
Age $(<45 ; 45$ to $80 ;>80)$ & 1.72 & 1.25 to 2.37 \\
McCabe score (for each point) & 2.92 & 1.01 to 8.93 \\
Chronic alcohol abuse & 1.37 & 1.24 to 1.51 \\
Total LODS day 0 (for each point) & 0.09 & 0.02 to 0.52 \\
Urinary tract origin of sepsis (pulmonary origin $=1$ ) & 4.04 & 1.82 to 8.93 \\
Model 2: & 1.68 & 1.21 to 2.34 \\
Age $(<45 ; 45$ to $80 ;>80)$ & 1.88 & 1.41 to 2.52 \\
McCabe score (for each point) & 1.5 & 1.17 to 1.93 \\
Neurological LODS (for each point) & 1.37 & 1.16 to 1.61 \\
Respiratory LODS (for each point) & 2.36 & 1.26 to 5.45 \\
Renal LODS renal (for each point) & 0.052 & 0.007 to 0.37 \\
Haematological LODS (for each point) & &
\end{tabular}

Cl, confidence interval; LODS, Logistic Organ Dysfunction System.

ver, our population was older than those of the other studies (median age, 68 years vs 61 to 65 years). Ferrer et al. [25], in a recent article dealing with the effects on outcome of a nationwide educational intervention based on the Surviving Sepsis Campaign guidelines, reported a basal hospital mortality rate of $44 \%$. Although slightly lower than ours, their patients had a lower age and APACHE II score. By contrast, the age of our patients was similar to those in the recent epidemiological study by Engel et al., found ICU (48.4\%) and hospital (55.2\%) mortality similar to our series [26].

At the time of diagnosis, our patients were severely ill; this is reflected by the prevalence of multiple organ failure $(78.1 \%$ had two or more organ failures and $50.4 \%$ had three or more) and the high LODS score (mean 6.3, median 6). This severity was confirmed in the first $24 \mathrm{~h}$ of evolution, with a high APACHE II score (median 25) and high organ dysfunction measured with the SOFA score (mean 9.6, median 10). This severity led to high early mortality: a quarter of the patients that died did so in the first $48 \mathrm{~h}$ and more than half of those who died did so in the first week (Figure 3). The 28-day mortality (47.9\%), although high, is closer to the results obtained in the previously cited studies. Although not statistically significant, the hospital stay prior to ICU admission seems to be associated with mortality; this association, together with the initial severity of our patients, could lead to a delay in diagnosis and initial resuscitation in septic patients in other areas of the hospital. Unfortunately, our study design did not include register- ing the time lag between the appearance of the first signs or symptoms of sepsis and the initiation of resuscitation measures and appropriate antibiotic therapy. The importance of establishing the diagnosis and treatment early is underlined by the factors that were associated with mortality in the first $48 \mathrm{~h}$ in the univariate study, including community-acquired infection and inappropriate initial antibiotic treatment. Other factors, such as the origin of the patients (hospital ward, emergency department) or their classification (medical or surgical) were in agreement with other studies $[14,26]$ and do not seem to be related to mortality. Chronic alcohol abuse was the only comorbid condition that was independently associated with increased mortality.

As in other recently published series [14,16,27], infection was most frequently located in the lungs, followed by the abdomen. Despite the increased number of Gram-positive infections registered in recent years $[12,14,27]$, the infections found in our patients were mostly caused by Gram-negative bacilli. The isolates and the percentage of the different microorganisms are similar to those published in the European study Sepsis Occurrence in Acutely III Patients (SOAP) [27], and the percentage of Gram-positive cocci is identical to that recently reported by Esteban et al. in Spain [10]. None of the microorganisms or sites of infection was independently associated with increased mortality. 
Table 5

Factors associated with hospital mortality present at the time of diagnosis of severe sepsis and over time

\begin{tabular}{|c|c|c|}
\hline & Odds ratio & $95 \% \mathrm{Cl}$ \\
\hline Age & 1.04 & 1.01 to 1.07 \\
\hline \multicolumn{3}{|l|}{ Site of infection: } \\
\hline Lung & 1 & \\
\hline Abdomen & 1.55 & 0.66 to 3.70 \\
\hline Catheter & 0.72 & 0.15 to 3.43 \\
\hline Urinary tract & 0.10 & 0.01 to 0.78 \\
\hline Others & 0.70 & 0.25 to 1.94 \\
\hline Chronic alcohol abuse & 3.20 & 0.90 to 11.42 \\
\hline Acquisition in hospital & 2.03 & 0.98 to 4.36 \\
\hline \multicolumn{3}{|l|}{ SOFA score day 1 (failure): } \\
\hline Haematological & 3.20 & 0.92 to 9.92 \\
\hline Cardiovascular & 2.78 & 1.37 to 5.64 \\
\hline Neurological & 2.39 & 0.76 to 7.48 \\
\hline Renal & 1.97 & 0.73 to 5.27 \\
\hline Liver & 1.67 & 0.46 to 6.08 \\
\hline Lung & 1.65 & 0.81 to 3.36 \\
\hline$\triangle$ SOFA (3-1) & 1.32 & 1.13 to 1.34 \\
\hline APACHE II Score & 1.02 & 0.97 to 1.08 \\
\hline Pre ICU stay (days) & 0.99 & 0.97 to 1.02 \\
\hline
\end{tabular}

APACHE II, Acute Physiology and Chronic Health Evaluation II; Cl, confidence interval; ICU: Intensive Care Unit; SOFA: Sepsis-related Organ Failure Assessment; SOFA failure: SOFA points 3 or 4 .

The relation between increased mortality and both the number of organ failures at diagnosis and the progression toward multiple organ failure in septic patients is well established [3$6,28]$. To document both the magnitude of organ failure at diagnosis and the sequential progression of organ failures, we used two specific indices, the LODS [21] and the SOFA [22], respectively. Both scores were independently associated with mortality. Introducing the LODS into the model displaced other risk factors such as the number of organ failures, the presence of shock or respiratory failure, and the number of comorbidities (Table 4, Model 1). The mortality associated with the failure of the different organs and systems at diagnosis was more clearly delineated when each of the components of the LODS score were analyzed separately (Table 4, Model 2). Moreno et al. reported in 1999 that the initial SOFA score could be used to quantify the degree of organ dysfunction or failure at admission and that there was a good correlation between organ failures assessed by the maximum SOFA score and mortality [29]. Ferreira et al. found a correlation between increased SOFA score in the first $48 \mathrm{~h}$ ( $\triangle$ SOFA 480 ) and mortality (OR 1.52) [30]. In our study, although the total SOFA score on day 1 was not independently associated with mortality and only one of its components (cardiovascular fail- ure) was associated with a significant increase in the risk of death, the difference between the SOFA score on days 1 and 3 ( $\triangle$ SOFA 3-1) was associated with a 1.3 times greater risk of death for each point increase in this difference. The SOFA score decreased over time in patients that survived, whereas it remained high in those that died. Comparing the area under the curve for the SOFA score obtained on days $1,3,5,7,11$, and 15 showed significant differences between survivors (5.78) and non-survivors (9.92), indicating that persistent organ failure is significantly associated with mortality (Figure $5)$.

Our study has some limitations. First, the absence of external monitoring by independent personnel not participating in data recollection might reduce the internal validity of the study. It was not possible to carry out a random review of clinical records at each of the participating centres, although all data were reviewed in the coordinating centre and extreme values were thoroughly checked to reduce errors before introducing them into the database. Second, although this is the largest specifically designed epidemiological study of severe sepsis in the ICU in Spain and despite that the specific geographical area we have studied is large, it is difficult to extrapolate our 
results to the general population and obtain firm conclusions about the prognosis of patients diagnosed with severe sepsis and attended in the ICU. Nevertheless, our results can serve as a reference for future studies about this condition in our environment. Third, the effect of seasonal variation on the incidence of sepsis is well known [31]. We divided the 6-month study period in two parts comprising spring-summer and autumn-winter to minimise seasonal variation, but its effects are difficult to measure. Fourth, we began our study shortly after the results of the PROWESS [16] study were published and activated protein $\mathrm{C}$ had not been approved for clinical use in Spain. The use of activated protein C [16] and steroids [32] was introduced in clinical practice for the treatment of severe sepsis after all the data for our study had been compiled. Subsequently, the Surviving Sepsis Campaign was launched, the SSC Clinical Practice Guidelines [18] were published, and the implementation of the resuscitation and management bundles were promoted by the SSC and the Institute for Healthcare Improvement $(\mathrm{IHI})$. It is likely that the use of activated protein $\mathrm{C}$ and the application of the measures promoted by the SSC and IHI have reduced the morbidity and mortality of septic patients admitted to the ICU after our study. Thus, our results can also be useful as a reference for future studies about the impact of these measures on the outcome of patients with severe sepsis admitted to the ICU in our setting. Fifth, although the data registration forms included a section for reporting the decision to limit treatment and withdraw life support, the lack of a valid unified 'do not resuscitate' protocol for all the ICUs participating in the study makes it impossible to reach conclusions about the influence of this type of decisions on hospital mortality in our series.

\section{Conclusion}

We found an incidence of severe sepsis attended in the ICU of $12.4 \%$, an estimated incidence of 25 cases of severe sepsis for every 100,000 inhabitants per year for the overall population, high ICU and hospital mortality (48.2\% and 54.3\%, respectively), and a prolonged hospital stay (median 24 days). Two or more organ failures were present at diagnosis in $78.1 \%$ of patients and $27.2 \%$ of those that died did so in the first $48 \mathrm{~h}$, which suggests delays in diagnosis, in initial resuscitation, and in beginning appropriate antibiotic treatment. Gram-negative bacteria caused $50 \%$ of the infections and pneumonia was the most common cause of severe sepsis in our environment. The LODS score was a good prognostic factor when determined at the moment of diagnosis. The evolution of organ failure assessed by the SOFA score was significantly different in survivors and non-survivors. The implementation of new treatment strategies in recent years and the development of the SSC measures for early diagnosis and resuscitation aimed at significantly reducing mortality in severe sepsis and septic shock necessitate new epidemiological studies to enable us to evaluate the efficacy of these measures.

\section{Key messages}

- In this prospective, observational, multicentre cohort study, we found a high incidence of severe sepsis in the ICU and high ICU and hospital mortality, and an association of severe sepsis with long ICU and hospital stays.

- The high prevalence of multiple organ failure at diagnosis and the high mortality in the first $48 \mathrm{~h}$ suggests delays in diagnosis, in initial resuscitation, and/or in beginning appropriate antibiotic treatment.

- The LODS score and the SOFA score were independently associated with mortality. The LODS score was a good prognostic factor when determined in the day of diagnosis of severe sepsis.

\section{Competing interests}

The authors declare that they have no competing interests.

\section{Authors' contributions}

The study was designed by JB and AM-B. They also initiated and coordinated the study, participated in the screening of patients, acquisition, analysis and interpretation of data, and they drafted and revised critically the manuscript. JV was involved in analysis and interpretation of data and he revised the manuscript critically for important intellectual content. VS, FT, FG, LT, JC, AG-L, DC, MV, MDeF, MJL, AC, JG and BA participated in study design, screening of patients and acquisition of data. AM was involved in analysis and interpretation of data and he made the principal statistical analysis. All members of the Grupo de Estudios y Análisis en Cuidados Intensivos (GRECIA) participated in the screening of patients and acquisition of data. All authors read and approved the final manuscript.

\section{Additional files}

The following Additional files are available online:

\section{Additional file 1}

A Word file listing the Members of Grupo de Estudios y Análisis en Cuidados Intensivos (GRECIA).

See http://www.biomedcentral.com/content/ supplementary/cc7157-S1.doc

\section{Additional file 2}

A Word file showing the definitions for intensive care unit (ICU) type, patient categories, comorbidities, systemic inflammatory response syndrome, sepsis, severe sepsis, septic shock and organ dysfunction.

See http://www.biomedcentral.com/content/ supplementary/cc7157-S2.doc 


\section{Acknowledgements}

The authors gratefully acknowledge the staff members and nursery of all hospitals involved in the study for their help and collaboration.

\section{References}

1. Martin GS, Mannino DM, Eaton S, Moss M: The epidemiology of sepsis in the United States from 1979 through 2000. N Engl J Med 2003, 348:1546-1554.

2. Bone RC, Balk RA, Cerra FB, Dellinger RP, Fein AM, Knaus WA, Schein RM, Sibbald WJ: Definition for sepsis and organ failure and guidelines for use of innovative therapies in sepsis. The ACCP/SCCM Consensus Conference Committee. American College of Chest Physicians/Society of Critical Care Medicine. Chest 1992, 101:1644-1655.

3. Brun-Buisson C: The epidemiology of the systemic inflammatory response. Intensive Care Med 2000, 26 Suppl 1:S64-S74.

4. Barriere SL, Lowry SF: An overview of mortality risk prediction in sepsis. Crit Care Med 1995, 23:376-393.

5. Brun-Buisson C, Doyon F, Carlet J, Dellamonica P, Gouin F, Lepoutre A, Mercier JC, Offenstadt G, Régnier B: Incidence, risk factors, and outcome of severe sepsis and septic shock in adults. A multicenter prospective study in intensive care units. French ICU Group for Severe Sepsis. JAMA 1995, 274:968-974.

6. Rangel-Frausto MS, Pittet D, Costigan M, Hwang T, Davis CS, Wenzel RP: The natural history of the systemic inflammatory response syndrome (SIRS): a prospective study. JAMA 1995, 273:117-123.

7. Sands KE, Bates DW, Lanken PN, Graman PS, Hibberd PL, Kahn $\mathrm{KL}$, Parsonnet J, Panzer R, Orav EJ, Snydman DR, Black E, Schwartz JS, Moore R, Johnson BL Jr, Platt R, Academic Medical Center Consortium Sepsis Project Working Group: Epidemiology of sepsis syndrome in 8 academic medical centers. JAMA 1997, 278:234-240.

8. Salvo I, de Cian W, Musicco M, Langer M, Piadena R, Wolfler A, Montani $C$, Magni E: The Italian sepsis study: preliminary results on the incidence and evolution of SIRS, sepsis, severe sepsis and septic shock. Intensive Care Med 1995, 21 Suppl 2:S244-S249.

9. Angus DC, Linde-Zwirble WT, Lidicker J, Clermont G, Carcillo J, Pinsky MR: Epidemiology of severe sepsis in the United States: analysis of incidence, outcome, and associated costs of care. Crit Care Med 2001, 29:1303-1310.

10. Esteban A, Frutos-Vivar F, Ferguson ND, Peñuelas O, Lorente JA, Gordo F, Honrubia T, Algora A, Bustos A, García G, Díaz-Regañón IR, de Luna RR: Sepsis incidence and outcome: contrasting the intensive care unit with the hospital ward. Crit Care Med 2007, 35:1284-1289.

11. Padkin A, Goldfrad C, Brady AR, Young D, Black N, Rowan K: Epidemiology of severe sepsis occurring in the first $24 \mathrm{hrs}$ in intensive care units in England, Wales, and Northern Ireland. Crit Care Med 2003, 31:2332-2338.

12. Annane $D$, Aegerter $P$, Jars-Guincestre MC, Guidet $B$, CUB-Réa Network: Current epidemiology of septic shock: the CUB-Réa Network. Am J Respir Crit Care Med 2003, 168:165-172.

13. Finfer S, Bellomo R, Lipman J, French C, Dobb G, Myburgh J: Adult-population incidence of severe sepsis in Australian and New Zealand intensive care units. Intensive Care Med 2004, 30:589-596.

14. Brun-Buisson C, Meshaka P, Pinton P, Vallet B, EPISEPSIS Study Group: EPISEPSIS: a reappraisal of the epidemiology and outcome of severe sepsis in French intensive care units. Intensive Care Med 2004, 30:580-588.

15. Alberti C, Brun-Buisson C, Burchardi H, Martin C, Goodman S, Artigas A, Sicignano A, Palazzo M, Moreno R, Boulmé R, Lepage $\mathrm{E}$, Le Gall R: Epidemiology of sepsis and infection in ICU patients from an international multicentre cohort study. Intensive Care Med 2002, 28:108-121.

16. Bernard GR, Vincent JL, Laterre PF, LaRosa SP, Dhainaut JF, Lopez-Rodriguez A, Steingrub JS, Garber GE, Helterbrand JD, Ely EW, Fisher CJ Jr, Recombinant human protein C Worldwide Evaluation in Severe Sepsis (PROWESS) study group: Efficacy and safety of recombinant human activated protein $\mathbf{C}$ for severe sepsis. N Engl J Med 2001, 344:699-709.

17. Angus DC, Wax RS: Epidemiology of sepsis: an update. Crit Care Med 2001, 29:S109-S116.
18. Dellinger RP, Carlet JM, Masur $\mathrm{H}$, Gerlach $\mathrm{H}$, Calandra $\mathrm{T}$, Cohen J, Gea-Banacloche J, Keh D, Marshall JC, Parker MM, Ramsay G, Zimmerman JL, Vincent JL, Levy MM: Surviving Sepsis Campaign Guidelines for management of severe sepsis and septic shock. Intensive Care Med 2004, 30:536-555.

19. McCabe WR, Jackson GG: Gram negative bateremia: etiology and ecology. Arch Intern Med 1962, 110:847-852.

20. Knaus WA, Draper EA, Wagner DP, Zimmerman JE: APACHE II: a severity of disease classification system. Crit Care Med 1985, 13:818-829.

21. Le Gall JR, Klar J, Lemeshow S, Saulnier F, Alberti C, Artigas A, Teres D: The Logistic Organ Dysfunction system. A new way to assess organ dysfunction in the intensive care unit. ICU Scoring Group. JAMA 1996, 276:802-810.

22. Vincent JL, Moreno R, Takala J, Willatts S, De Mendonça A, Bruining $\mathrm{H}$, Reinhart CK, Suter PM, Thiis LG: The SOFA (Sepsis Related Organ Failure Assessment) score to describe organ/ dysfunction/failure. On behalf of the Working Group on Sepsis-Related Problems of the European Society of Intensive Care Medicine. Intensive Care Med 1996, 22:707-710.

23. Garner JS, Jarvis WR, Emori TG, Horan TC, Hughes JM: CDC definitions for nosocomial infections. Am J Infect Control 1988 16:128-140.

24. Instituto Nacional de Estadística (INE): Censo de Población y Viviendas 2001. [http://www.ine.es/jax menu.do?type $=$ pcaxis\&path $=\% 2 \mathrm{Ft} 20 \% 2 \mathrm{Fe} 242 \&$ file $=$ inese\&L=].

25. Ferrer R, Artigas A, Levy MM, Blanco J, González-Díaz G, Garnacho-Montero J, Ibáñez J, Palencia E, Quintana M, de la Torre-Prados MV, Edusepsis Study Group: Improvement in process of care and outcome after a multicenter severe sepsis educational program in Spain. JAMA 2008, 299:2294-2303.

26. Engel $C$, Brunkhorst FM, Bone $H G$, Brunkhorst $R$, Gerlach $H$ Grond S, Gruendling M, Huhle G, Jaschinski U, John S, Mayer K, Oppert M, Olthoff D, Quintel M, Ragaller M, Rossaint R, Stuber F, Weiler N, Welte T, Bogatsch H, Hartog C, Loeffler M, Reinhart K: Epidemiology of sepsis in Germany: results from a national prospective multicenter study. Intensive Care Med 2007, 33:606-618.

27. Vincent JL, Sakr Y, Sprung CL, Ranieri VM, Reinhart K, Gerlach H, Moreno R, Carlet J, Le Gall JR, Payen D, Sepsis Occurrence in Acutely III Patients Investigators: Sepsis in European intensive care units: results of the SOAP Study. Crit Care Med 2006, 34:344-353.

28. Alberti C, Brun-Buisson C, Chevret S, Antonelli M, Goodman SV, Martin C, Moreno R, Ochagavia AR, Palazzo M, Werdan K, Le Gall JR, European Sepsis Study Group: Systemic inflammatory response and progresion to severe sepsis in critically ill infected patients. Am J Respir Crit Care Med 2005, 171:461-468.

29. Moreno R, Vincent JL, Matos R, Mendonça A, Cantraine F, Thijs L, Takala J, Sprung C, Antonelli M, Bruining H, Willatts S: The use of maximum SOFA score to quantify organ dysfunction/failure in intensive care. Results of a prospective, multicentre study. Intensive Care Med 1999, 25:686-696.

30. Ferreira FL, Bota DP, Bross A, Mélot C, Vincent JL: Serial evaluation of the SOFA score to predict outcome in critically ill patients. JAMA 2001, 286:1754-1758.

31. Danai PA, Sinha S, Moss M, Haber MJ, Martin GS: Seasonal variation in the epidemiology of sepsis. Crit Care Med 2007 35:410-415

32. Annane $D$, Sébille $V$, Charpentier $C$, Bollaert $P E$, François $B$, Korach JM, Capellier G, Cohen Y, Azoulay E, Troché G, ChaumetRiffaut $P$, Bellissant $E$ : Effect of treatment with low doses of hydrocortidsone and fludrocortisone on mortality in patients with septic shock. JAMA 2002, 288:862-871. 